\title{
Elementary Analysis of the Mechanism of Xishan Landslide Based on Pixel Tracking on VHR Images
}

\author{
Beiqi Shi ${ }^{*}$, Chun $\mathrm{Liu}^{2}$, Hangbin $\mathrm{Wu}^{2}$, Ping $\mathrm{Lu}^{2}$ \\ ${ }^{1}$ Shanghai Institute of Tourism, Shanghai Normal University, Shanghai, China, 201418 \\ ${ }^{2}$ TongJi University, Shanghai, China, 200092
}

\begin{abstract}
The geometric and kinematic characterizations of landslides are key factors for understanding the mechanisms of landslide movement. Recent developments in remote sensing techniques provide powerful tools for landslide deformation studies. The objective of this paper is to present an efficient method for monitoring the horizontal ground displacement and strain field of active landslides from spaceborne optical images, which were analyzed with a digital image correlation technique. This method was evaluated on a series of images acquired on the Xishan landslide in China over the period between 2010 and 2013. These imageries included ZY-3 and WorldView-II images. These were Very High Resolution (VHR) satellite imageries and were orthorectified with a high resolution DEM interpolated from Unmanned Aerial Vehicle (UAV). By using sub-pixel correlation on before- and after-event orthoimages, it was possible to compute the displacement field with high planimetric resolution. Furthermore, a strain analysis was performed to characterize the deformation and displacement regime of the landslide. Validation of the computed strain field analyzed the relationship between the deformation and the faults detected in the field. This approach can facilitate displacement measurements. It could, therefore, offer promising potential for operational applications, for instance, early warning of geo-hazards.
\end{abstract}

Keywords: landslide, deformation monitoring, Very High-Resolution Imagery, digital image correlation, strain analysis

\section{Introduction}

Landslides are major natural hazards that threaten infrastructures and human settlements. Reliable decisions should be made on the basis of a deep understanding of the landslide behavior. Deformation monitoring of landslide surface is essential to provide information on the geometry of the ruptured fault and understand tectonic and geomorphological processes.

Landslide slope displacement as a type of surface deformation is correlated with different phenomena (Watson et al 2004) such as piezometric level changes. Historical analysis demonstrates that the rise of water table level is often followed by displacements in the sliding area as a result of changing pressures and stresses on the body of the landslide (Baron et al 2012). Furthermore, strain of objects can be expressed using the stress field. This measurement is independent with respect to rigid body motions, evidencing real relative surface variations. Accordingly, the estimated strain allows the identification of zones characterized by different kinematics (Teza et al 2008).

Several instruments are available for deformation monitoring on landslide surface. Field measurement, such as Global Positioning System (GPS), is one of the most common methods for measuring displacement (Mora et al 2003); this

*Corresponding Author: Beiqi Shi, Email: carashi@ 163.com, Tel: +86 (021) 6432-2996 
measurement involves repeated surveys of discrete points on the land surface. Such a method can provide measurements at high temporal resolution. However, the fault area is often difficult to access and complex fault ruptures are arduous to detect in the field. Depending on the extent of the fault slip, such technique is limited by the spatial distribution of fault ruptures. Sparse area can be measured via Global Navigation Satellite System (GNSS). Similar to GNSS, a few other surveying sensors, such as total station, specially the robot total station, are particularly used for landslide monitoring (Tsai et al 2012).

Remote sensing is an important tool to investigate landslide kinematics and has the ability to obtain spatially distributed data without the need for physical access to the site. Satellite imagery using Synthetic Aperture Radar (SAR) works in all weather and nighttime acquisitions (Massonnet and Feigl 1998). Thus, SAR interferometry is applied for monitoring mass movements (Kimura and Yamaguchi 2000, Nagler et al 2002, Colesanti and Wasowski 2006, Farina et al 2008, Lu et al 2012, 2014, Crosetto et al 2013). However, SAR has difficulty providing displacement maps in the near field of the fault because the large amplitudes of the displacements present in the landslide area cause the de-correlation of the interferometry phase. Ground-based Interferometric Synthetic Aperture Radar (GB-InSAR) can also provide a relatively dense displacement map with high accuracy in landslide deformation measurement (Antonello et al 2004, Herrera et al 2009, Monserrat et al 2013); yet, this tool suffers a few limitations, such as the noise of the point, so-called aliasing effect, and atmospheric component of the interferometric phase (Monserrat et al 2013). Furthermore, only the line-of-sight component of the displacements is acquired, and a model based on appropriate assumptions is required to reconstruct the entire displacement field. As another displacement measurement technique, Terrestrial Laser Scanner (TLS) generates highresolution and highly accurate digital models of the observed surface and is exploited for monitoring geomorphologic processes (Abellán et al 2009, Kasperski et al 2010, Travelletti et al 2014).
However, the displacement rate is often significantly low that long-term monitoring is required for a satisfactory assessment of the landslide kinematics. Moreover, the comprehensive mechanism of movement and the relative effects of different influencing factors require an accurate evaluation of the time trend of movement. Ground-based monitoring methods for such mass movements can be costly, time consuming and limited in spatial and temporal coverage. Relatively high-frequency data recording is necessary. Remote sensing techniques matching repeat optical images are increasingly used to analyze displacement and deformation fields. High-resolution optical satellite imagery provides detailed images of the ground with repeated pass cycles and higher spatial resolutions as well as enhanced capabilities for the acquisition of monoscopic, stereo, and multi-view image datasets. In addition, this technique is able to detect the near-fault displacement (Van Puymbroeck et al 2000). The displacement field can be determined with pixel tracking. Digital Image Correlation (DIC) method as pixel tracking directly provides full-field displacements and strains by comparing the digital images of the specimen surface in the undeformed (or reference) and deformed states. This method has been widely accepted and is commonly considered as a powerful and flexible tool for earth-surface deformation analysis (Delacourt et al 2004, Leprince et al 2007, Heid and Kääb 2012, Booth et al 2013). Studies on sub-pixel correlation applied to high-resolution satellite images to measure the displacements smaller than the image pixel size are numerous (Michel and Avouac 2002, Debella-Gilo and Kääb 2011). In general, high-resolution satellite images with a ground pixel size of $2.5-10$ $\mathrm{m}$ are used, the smallest $2 \mathrm{D}$ displacements that may be measured are 0.25 - $1 \mathrm{~m}$ (Rosu et al 2014) or the accuracy of 2D displacements (in pixels) that may be evaluated is about 0.2 pixels (Casson et al 2005, Delacourt et al 2007) in the image plane. In various tasks of landslide zone identification characterized by different kinematics, full-field strain distributions are more important and desirable than displacement measurement. Fullfield strain measurement is independent with respect to rigid body motions, evidencing real 
relative surface variations only. As an optical metrology based on digital image processing and numerical computing, DIC can also estimate strain field (Pan et al 2009). Thus, the image acquisition system combined with the landslide displacement detector code provides a low-cost method for the surface displacement survey of landslides. It permits to simply analyze many points on a landslide with the condition that they are well distinguishable from the background.

Xishan landslide is one of the deep and creep active landslides in Sichuan Province, China. This landslide is a latent major natural hazard that threatens infrastructures and human settlements. This study investigates the usage of highresolution satellite images for the analysis of its surface deformations, including displacement and strain-field analysis. Sub-pixel DIC is proposed to obtain the understanding of tectonic and geomorphological processes. Thus, the performance of the method is applied for data sets acquired at Xishan landslide. Firstly, the main geomorphological and kinematical characteristics of the landslide are introduced. Section 2 presents data sets descriptions and preprocessing. Methodologies to determine the displacement and strain field are described in Section 3. In section 4, the results are explained to characterize the deformation and displacement regime of the landslide and to identify a few possible controlling factors. The limitations of the proposed method and several ideas for future work are discussed in Section 5. Finally, the conclusions are presented in Section 6.

\section{Experimental Site and Data Set}

\subsection{Experimental site: Xishan landslide overview}

Xishan landslide represents the large retrogressive mudslide located in Li County, Sichuan Province, Southwest China (Fig. 1). The landslide is about $60 \mathrm{~km}$ away from Yingxiu town, which is the center of Wenchuan earthquake where a large number of landslides were triggered after the

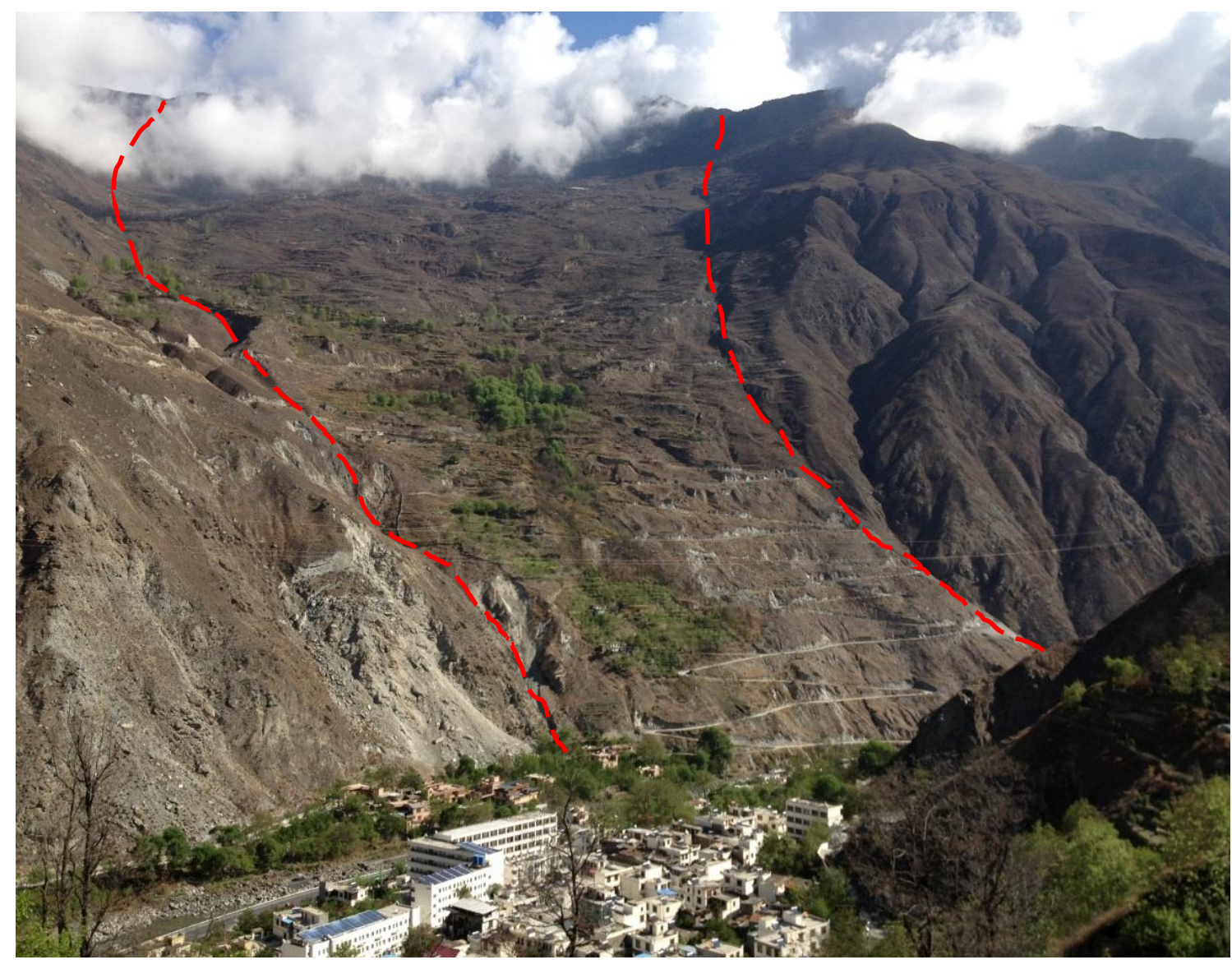

Fig. 1 (a) Xishan landslide 


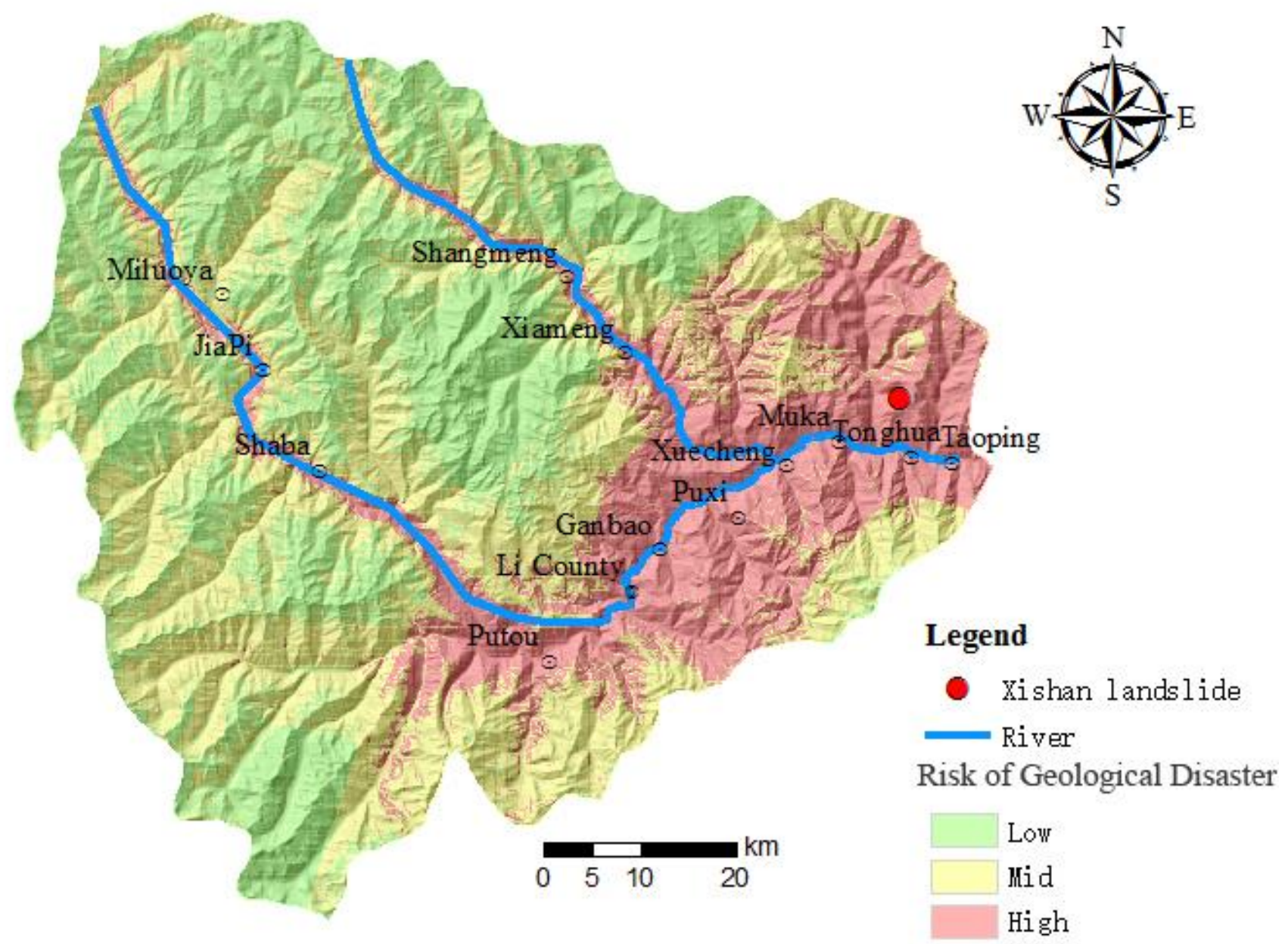

(b) Location in Li county

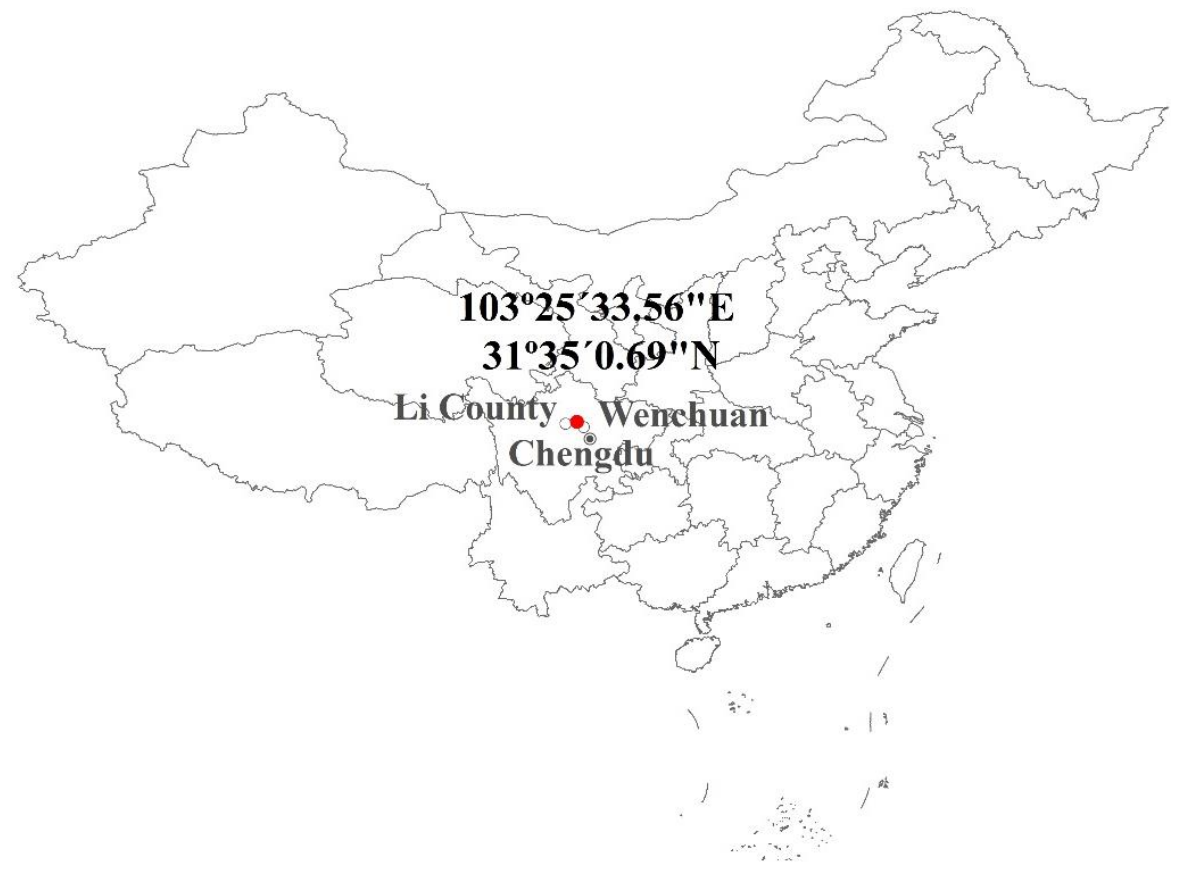

(c) Location in China

Fig. 1 Experimental site: Xishan landslide 
earthquake in 2008 and future mass movements may occur. Geographically, the area belongs to eroded deep valleys, as a result of the effect of the Zagunao River. This area is also influenced by monsoon climate with rainstorms. The high precipitation within a summer season (May September) implies high runoff and well saturated soils. Xishan landslide is in the areas of high relief with slopes in the range of $25^{\circ}-45^{\circ}$. The northsouth vertical distance of this area is $4200 \mathrm{~m}$ and the horizontal east-west width distance is $1700 \mathrm{~m}$. The toe front elevation is $1500 \mathrm{~m}$, and the scarp elevation is $2910 \mathrm{~m}$, thus creating an elevation difference of about $1410 \mathrm{~m}$. According to a previous in situ field survey, the expected landslide volume is over $1.7 \times 10^{8} \mathrm{~m}^{3}$ and its sliding direction is about $201^{\circ}$. The landslide exhibits cumulated displacements and is characterized by continuous movements because of a non-obstructing sloping path and frequent enrichment of material from the main scarp.

Preliminary results of recent surveys showed that the stability of the landslide was poor and the area was affected by slow movements with highly complex and unclear kinematics. Before the Wenchuan earthquake, several surface fissures and dislocations existed in the front or middle of Xishan landslide. Residential buildings were in different degrees of crack, tilt, and even partial dump. The direct economic losses cost approximately 50 million RMB, and 56 neighborhoods, including 189 persons, were in danger. In 2008, the Wenchuan earthquake severely damaged and even collapsed residential buildings. Continued deformation with expanded cracks around Xishan landslide was observed in a few buildings. This phenomenon illustrated that the landslide was deforming, seriously threatening the safety of life and property. More than 158 neighborhoods with 586 persons in Xishan village, 38 neighborhoods with 108 persons in Tong-hua village, and 15 neighborhoods with 48 persons in Ka-zi village were predicted to be threatened. These villages locate within the red lines shown in Fig. 1(a). The deformation also influenced the traffic safety of $20 \mathrm{~km}$ of rural roads, Zagunao River, and National Road G317.

\subsection{Data set and preprocessing}

The latest generation of VHR satellites featuring shorter repeated pass cycles and higher spatial resolutions can meet the requirement for the field investigation. Multi-temporal WorldView-II panchromatic images with $0.5 \mathrm{~m}$ spatial resolution acquired on January 17, 2010 and February 3, 2013 were used to estimate the trend of displacement and derive the characteristics of the Xishan landslide deformation. Another two scenes of ZY-3 panchromatic images with $2.1 \mathrm{~m}$ spatial resolution acquired on December 7, 2012 and August 5, 2013 were used for strain-field and displacement analyses. The obtained displacement fields provide useful information for the landslide hazard assessment. The estimated strain allows the identification of zones characterized by different kinematics.

Obtaining accurate geometric registration of satellite imagery data to a common spatial framework is a principal requirement for image analysis. Without topographic correction, the offset or disparity map will include a tectonic displacement overprinted by a much larger topographic signal as a result of the parallax difference between the two images. The steps in the data processing workflow are applied in the original rational polynomial function sensor model and orthorectification of images with DEM. Ideally, different DEMs should be applied to each correlated image with various viewing angles. Unfortunately, the limited availability of DEM precludes such accuracy. In this study, only one precise DEM was extracted with a pixel spacing of $2 \mathrm{~m}$ (WGS84 UTM 48N) from UAV imageries acquired on May 12, 2013. DEM was applied for orthorectification. Both DEM and 54 ground control points were deployed for the correlated images with a common geometry.

In this study, a commercial software solution, ENVI 5.0 RPC Orthorectification method (Exelis Visual Information Solutions 2012), was used for image geometric correction. The accuracy of VHR imagery orthorectification is shown in Table 1. Co-registration has been improved by using numerous and accurate homologous points. This method yields two images co-registered within a few tenths of a pixel. 
Therefore, orthorectification provided multitemporal images with a common viewing geometry, equivalent to the satellite looking exactly normal to the Earth's surface everywhere across the image. These images can then be correlated to measure horizontal tectonic displacements.

Table 1 Accuracy of VHR imagery orthorectification

\begin{tabular}{cccc}
\hline Image & X residual (pixel) & Y residual (pixel) & RMSE (pixel) \\
\hline WorldView-II (17/01/2010) & 0.657 & 0.801 & 1.017 \\
\hline WorldView-II (03/02/2013) & 0.713 & 0.795 & 1.029 \\
\hline ZY-3 (07/12/2012) & 0.682 & 0.709 & 0.984 \\
\hline ZY-3 (05/08/2013) & 0.669 & 0.713 & 0.978 \\
\hline
\end{tabular}

\section{Methodologies of Landslide Deformation Measurement}

\subsection{Digital image correlation method for displacement}

Measuring the offset of pixels tracking in two consequent images of the same landslide area using DIC can obtain information on the direction and magnitude of horizontal surface displacements. DIC allows displacement detection by considering mathematical cross-correlation of digital photography data sets (Delacourt et al 2004, Heid and Kääb 2012, Travelletti et al 2012, Stumpf et al 2014). According to this image matching method, the first image (often the pre-event) is selected as the reference image and a correlation window is defined on a reference image. A corresponding window is searched in a pre-defined explored area belonging to the second image (the after-event). Then, the centered normalized cross-correlation surface (NCC) is given by Eq. (1).

$$
N C C(i, j)=\frac{\sum_{k, l}\left(s(i+k, j+l)-\mu_{S}\right)\left(r(k, l)-\mu_{r}\right)}{\sqrt{\sum_{k, l}\left(s(i+k, j+l)-\mu_{S}\right)^{2} \sum_{k, l}\left(r(k, l)-\mu_{r}\right)^{2}}}
$$

where $(i, j)$ is the position in the search area, $(k, l)$ is the position in the reference area, $r$ is the pixel value of the reference chip, $s$ is the pixel value of the search chip, $\mu_{r}$ is the average pixel value of the reference chip, and $\mu_{s}$ is the average pixel value of the search chip. The peak of the cross-correlation surface indicates the displacement between the images.
The process is repeated for each pixel of the reference image. The correlation output of georeferenced images includes two disparity maps with relative horizontal displacements in east-west or north-south and each pixel correlation score. Finally, the Euclidean distance between the reference point and the matching point represents the displacement amplitudes in the image plane. The displacement direction can also be calculated from the output.

In recent years, several sub-pixel image correlation techniques have been developed. A number of sophisticated algorithms have been implemented in software tools, such as Correli (Hild and Roux 2008), CIAS (Kääb 2013), COSICorr (Ayoub et al 2009), Medicis (CNES, France), PICMATCH (JPL, USA), and MicMac (PierroDeseilligny 2014). In this study, MicMac, a free open-source software, was applied to compute multi-image sub-pixel correlation in the spatial domain. By using regularization technique, MicMac provides a good solution to the problem of the correlation window size, which traditionally is a compromise between the requested measurement accuracy and the amplitude of the displacement. When regularizing, MicMac uses multi-directional dynamic programming with an energy minimization approach based on the "data attachment term" (representing the data consistency) and the "regularization term" (expressing the a priori assumption of surface regularity) (Pierro-Deseilligny and Paparoditis 2006). MicMac also provides non-linear costs associated with the normalized cross-correlation 
coefficient to concur the corruption of measurements in well-correlated areas by poorcorrelated areas. The availabilities of vulnerability to noise and dealing with large spatial inhomogeneities as a result of long time intervals allow MicMac to meet the experiment requirements.

Based on the MicMac manual, main parameters were set according to data-driven processing. To measure small displacements of Xishan slowmoving landslide, a sinus cardinal interpolation was applied and an apodization window was transformed into a Hamming window instead of a Tukey window. As the MicMac sub-pixel matching method has theoretical precision of about $1 / 10 \mathrm{px}$ on diachronic synthetic images (Rosu et al 2014), the size of the correlation window was set as $9 \times 9$ px. The parameters of non-linear costs of image term consist of a correlation threshold $C^{\min }$ and $\gamma$, which controls the influence of correlation scores. Here, $C^{\text {min }}$ of WorldView-II was set as 0.760 and $C^{\text {min }}$ of ZY-3 was set as 0.754 , yielding the computed correlation coefficients. $\gamma$ was set to the default value of 2 . The calculation of the image term has the same effect as the traditional postfiltering to remove the outlier values of computed displacements (Travelletti et al 2012) for the low correlation coefficient values caused by important deformation or rotation of the tracked object in the interrogation image. Regularization term was set to the default value 0.3 .

\subsection{Determination of the strain field}

By using DIC, the displacement field can be obtained in sub-pixel accuracy. Furthermore, in various tasks of landslide kinematics analysis, strain field distributions are more important and desirable. Accordingly, in slow-moving landslide, shear distortions occur within landslides during the time before large surge displacements and are caused by the reactivation of failure at residual strength in basal shear zones. These estimated strains are potentially useful indicators of the main movements. Stress and strain within the landslide deformation also influence the distribution of surficial faults. Strain fields can also define the complex interactions between mechanical and fluid properties and states and can provide proxies for analyzing rheology of the material.
Alternatively, the strains can be computed as a numerical differentiation process of the estimated displacement. The strain fields can be determined with the 2D Cauchy strain tensor $\mathrm{E}$ from displacements in horizontal plane (Wattrisse et al 2001, Pollard and Fletcher 2005). In particular, the strain tensor $\mathrm{E}$ is symmetric and represents the internal deformation, which can be written in the following form:

$E=\left[\begin{array}{cc}\frac{d u}{d x} & \frac{1}{2}\left(\frac{d u}{d y}+\frac{d v}{d x}\right) \\ \frac{1}{2}\left(\frac{d u}{d y}+\frac{d v}{d x}\right) & \frac{d v}{d y}\end{array}\right]$

where $u=\Delta X$ and $v=\Delta Y$ refer to the incremental displacement along the $\mathrm{x}$ - and $\mathrm{y}$ directions in the coordinate system.

The implementation of the local least-squares fitting technique for 2D strain estimation can be explained as follows (Pan et al 2009). The strain calculation window is selected as a square window containing $(2 m+1) \times(2 m+1)$. If the value is small enough, then the displacement distributions can be approximated as a linear plane, as shown in Eq. (3) (Pan et al 2009).

$\mathrm{u}(\mathrm{i}, \mathrm{j})=\mathrm{a}_{0}+\mathrm{a}_{1} x+\mathrm{a}_{2} y$

$v(\mathrm{i}, \mathrm{j})=\mathrm{b}_{0}+b_{1} x+\mathrm{b}_{2} y$

where $i, j=-m: m$ are the local coordinates within the strain calculation window, $u(i, j)$ and $v(i, j)$ are the original displacements at location $(i, j)$ obtained by DIC displacement as indicated, and $a_{i}=0,1,2$, $b_{i}=0,1,2$ are the unknown polynomial coefficients to be determined. The least-squares method provides a solution for the unknown polynomial coefficients by rewriting Eq. (3) as matrix formulation in Eq. (4).

$$
\left[\begin{array}{ccc}
1 & -m & -m \\
1 & -m+1 & -m \\
\vdots & \vdots & \vdots \\
1 & 0 & 0 \\
\vdots & \vdots & \vdots \\
1 & m-1 & m \\
1 & m & m
\end{array}\right]\left(\begin{array}{l}
a_{0} \\
a_{1} \\
a_{2}
\end{array}\right)=\left\{\begin{array}{c}
u(-m,-m) \\
u(-m+1,-m) \\
\vdots \\
u(0,0) \\
\vdots \\
u(m-1, m) \\
u(m, m)
\end{array}\right\}
$$


The component of the Cauchy strain tensor are estimated with $a_{1}=\frac{d u}{d x}, a_{2}=\frac{d u}{d y}, b_{1}=\frac{d v}{d x}, b_{2}=$ $\frac{d v}{d y}$. As mentioned, the strain tensor $E$ is real and symmetric, the two eigenvalues corresponding to the change per unit length in the direction having the maximum $\left(e_{\max }\right)$ and minimum $\left(e_{\min }\right)$ extension, positive for extensions, and the corresponding eigenvectors are the principal strain directions. The normalized shear is estimated as $\left(e_{\max }-e_{\min }\right) /\left(e_{\max }\right.$ $\left.+e_{\min }\right)$, the difference of the maximum and minimum strains normalized to their sum, which has the same sign of the eigenvalue whose modulus is

prevalent.

When

$\left|e_{\max }\right|<<\left|e_{\min }\right|$ or $\left|e_{\max }\right|>>\left|e_{\min }\right|$, the normalized shear tends to +1 if the extensional strain prevails, or to -1 if the prevalent strain is compressive; the predominance of one component with respect to the other is highlighted. When $\left|e_{\max }\right| \cong\left|e_{\min }\right|$ and the extreme eigenvalues have the same sign, the shear is about 0 , whereas it diverges if the signs are opposite. The normalized shear identifies eventual differences in the behavior of the different parts of the landslide ground surface. In this way, eventual discontinuity planes, such as fissures, faults, or boundaries between areas with different kinematics in earth flows in landslides, can be detected (Teza et al 2008). Moreover, $e_{\max }+e_{\min }$ is calculated for the change in per unit area, which means the trace of the strain tensor. It is the representative of the areal deformation with a negative to positive variation.

In the experiment, a regular grid $(30 \times 30)$ displayed a homogenous distribution of the displacements from ZY-3 data source. Based on this mesh grid, a strain window of $3 \times 3$ was selected for least-squares fitting calculation. Finally, strain tensors, change in area, and normalized shear pattern of Xishan landslide were determined by the method.

\section{Result Analysis}

\subsection{Displacement field}

The findings of Stumpf et al (2014) show that GCPs are important for accurate absolute georeferencing of the DSM and the displacement maps; however, GCPs have a minimal effect on the absolute values of the measured displacement. Normalized crosscorrelation method has calculated displacement fields without GCPs.

For the period January 2010 to February 2013, displacements between $0.015 \mathrm{~m}$ and $3.952 \mathrm{~m}$ were observed, corresponding to an average displacement rate of $0.001-0.521 \mathrm{~cm} \mathrm{day}^{-1}$ (Fig. 2a). The displacement field exhibited significant spatial variability. The largest displacements were detected at the trailing edge of the front where the slope gradient increases. The detachment of a small compartment is also highlighted in cracks. During the following year (December 2012 to August 2013), extremely different kinematics was observed both in terms of magnitude and spatial distribution. Displacements were shorter and range from $0 \mathrm{~m}$ to $0.334 \mathrm{~m}$, corresponding to an average rate of 0.001-0.124 $\mathrm{cm} \mathrm{day}^{-1}$ (Fig. 2b).

\subsection{Strain field analysis}

When the DIC method is used on ZY-3, the steps computing strain field is similar to that of the displacement field in the Xishan landslide. The strain field tensors, consisting of the principal strain directions (eigenvectors) and eigenvalues in each computation point of the grid nodes. The corresponding eigenvectors are the principal strain directions. The eigenvector lengths are proportional to the eigenvalues. Starting from a given displacement (or velocity) data set, a deformation pattern can be estimated, which provides elements to study the morphological surface evolution, or also on the stress state of the ground surface.

Thus, the strain analysis allows discriminating mechanical units in extension, compression, and is affected by shearing. The slope is controlled by two principal strain axes, which are mean-oriented SSE-NNW and ENE-WSW (Fig. 3). However, the eigenvalues were opposite signs in the landslide trailing edge. One of the principal directions is related to compressive strain, and the other is associated with extension. In particular, the compressive strains (red arrows) generally have an ENE-WSW direction, whereas the extensional strains (blue arrows) are orthogonal and perpendicular to the sliding direction. The strain is in the $-1.8 \times 10^{-6}$ to $5.7 \times 10^{-6}$ range, and appears to be reasonable if we consider the estimated 

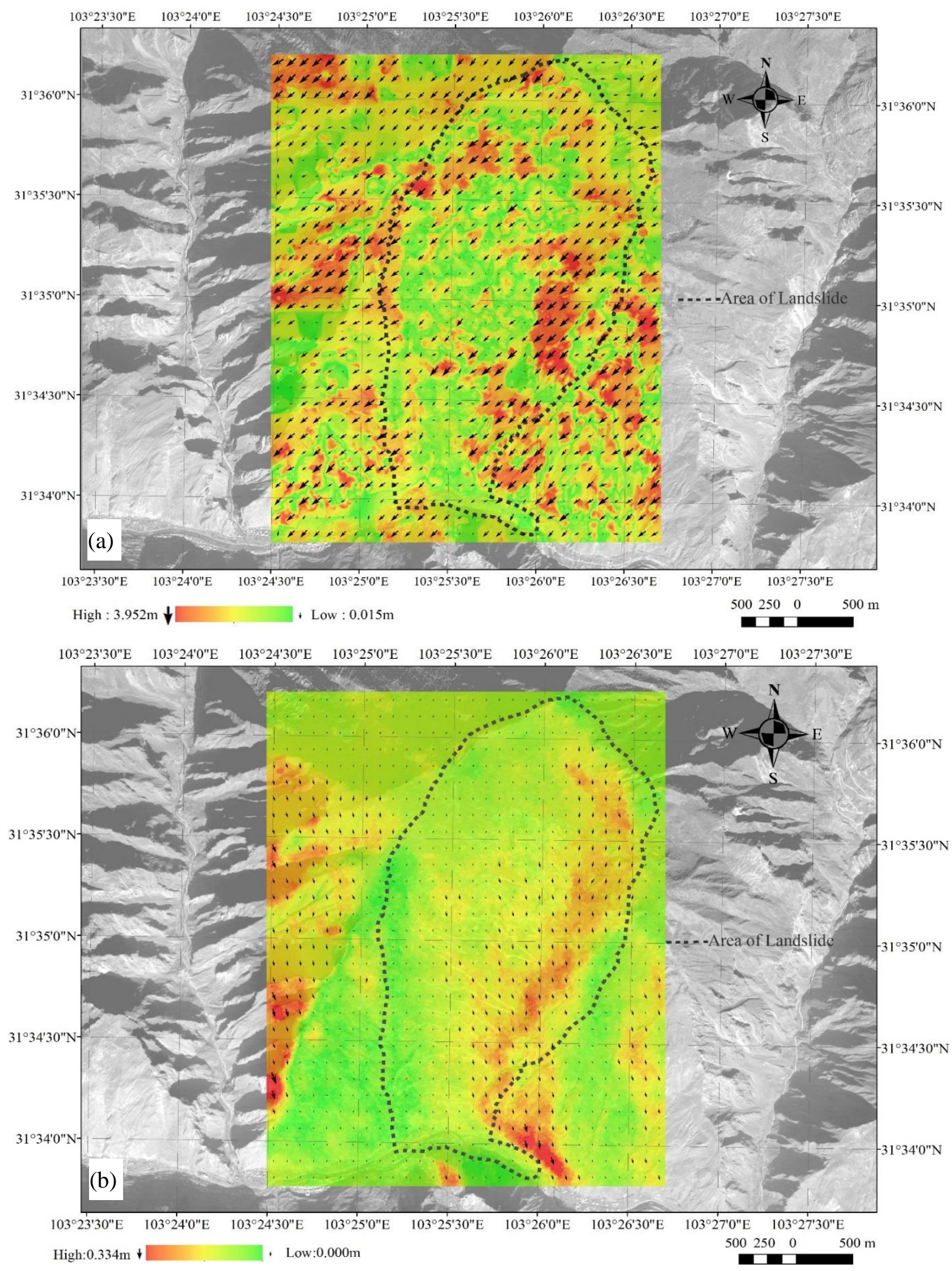

Fig. 2 Result of horizontal displacement measurement: (a) displacement measurement from WorldView-II (January 2010 February 2013); (b) displacement measurement from ZY-3 (December 2012 - August 2013) 


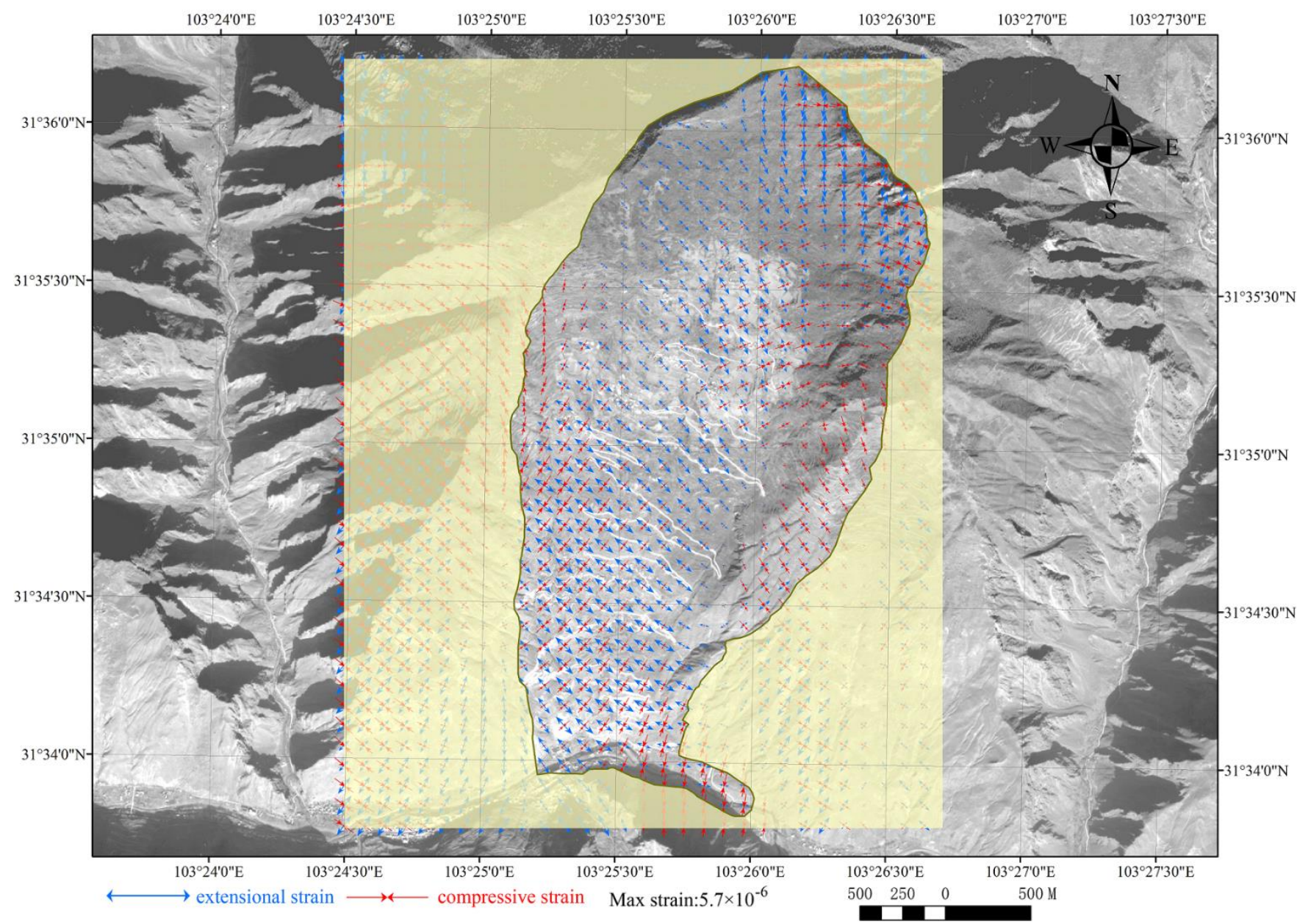

Fig. 3 Map of the surface strain. Stain Factor: $117 \mathrm{~m}$

displacement and the landslide size (a few thousand meters).

The estimate of the shear normalized to the strain matrix trace is computed as the quantity of $\left(e_{\max }-e_{\min }\right) /\left(e_{\max }+e_{\min }\right)$. When the values of $e_{\max }$ and $e_{\min }$ have the same signs, the normalized shear function converges to 0 , whereas it diverges if the signs are opposite. The normalized shear can provide information about the sign of both principal strains and show the nature and the geometry of strain tensor, allowing a better characterization of the deformation pattern. The deformation of the ground surface and the accumulated stress are presented in Fig. 4. This figure also shows the contour maps of the normalized shear pattern which identifies eventual differences in the behavior of the different parts of the landslide ground surface. The Xishan landslide slope is in the zone where the normalized shear changes from $\sim 0$ (few tens; thus, the extension is slightly prevalent in the north part) to -200 (prevalence of compression in the edge of the eastern or western part). This fact indicates complex kinematics of the landslide with a split along the NNE-SSW direction, which is along the maximum topographical gradient. Therefore, the entire kinematics of the landslide shows a prominently radial behavior. According to an in situ survey in 2014, the consequence of extension results in the development of tensile faults is identifiable in the field. The toe front is also affected by important shearing concentrated along the landslide boundary. In fact, the technique provides information on the behavior of the landslide.

Furthermore, the trace of the strain tensor is the change in area, which is the representative of the areal deformation with a negative to positive variation. Even if the change in area of Xishan Landslide is almost positive, some zones with 


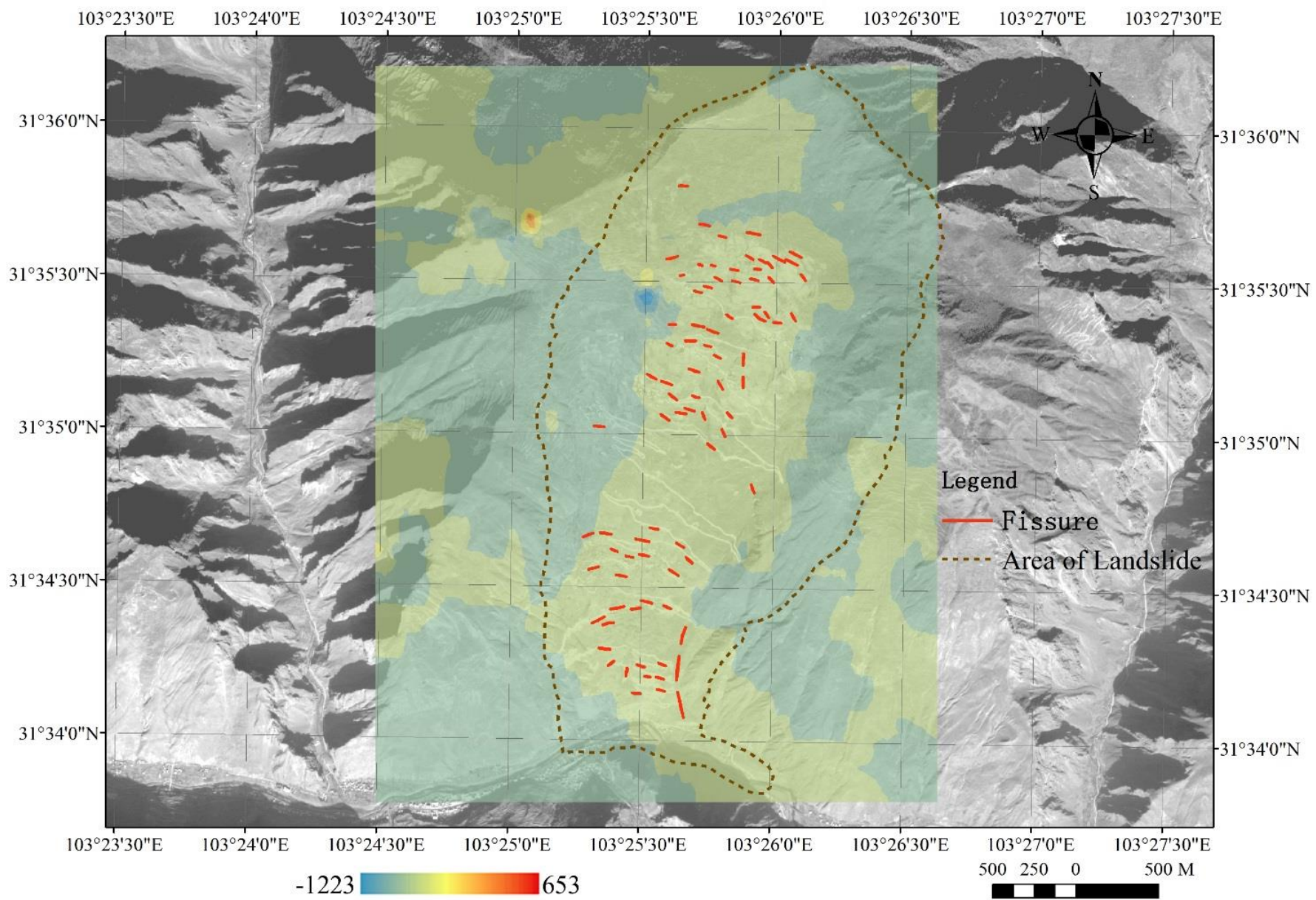

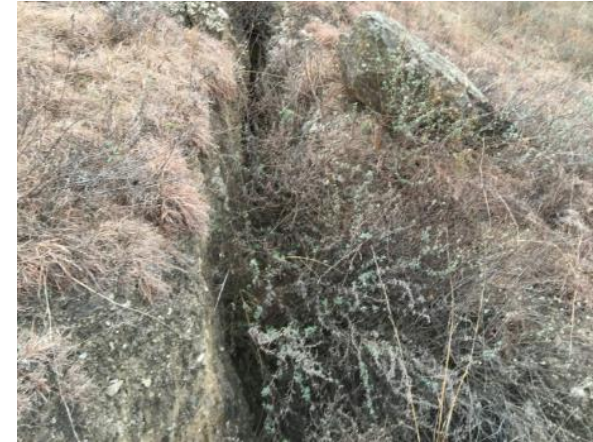

Fissures on hillside

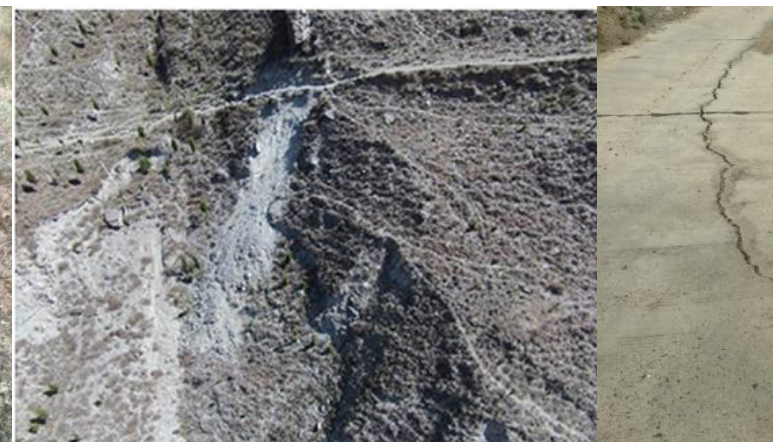

Collapse on hillside

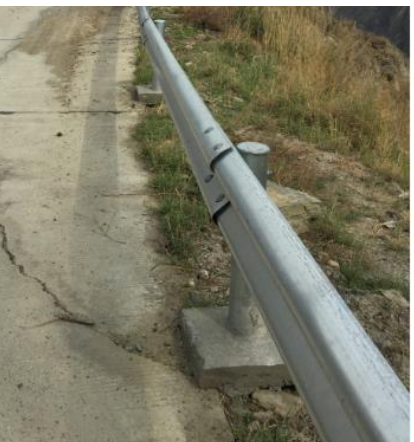

Cracks on road

Fig. 4 Map of normalized shear

different kinematics can be recognized. In the studied landslide, the differences in kinematics arise where the slope angle changes and are almost aligned to faulted source structures. Thus, the strain change in area per unit area shows that the slope area of the landslide positively increased. The estimated strain could allow the identification of zones characterized by different kinematics (Fig. 5). On the basis of the contour map of the strain change area, the slope area can be characterized into three zones. The three zones are the local perturbations with faults on regional scale recognized by means of the strain analysis.

Area I locates at the front edge of the landslide. Obvious deformations are detected at Area I, which caused by fluvial incision of Zagunao River. Area II is at the mid part of the landslide, where exists cracks and fissures. Frequent enrichment of materials are at the trailing edge of the landslide in Area III. 


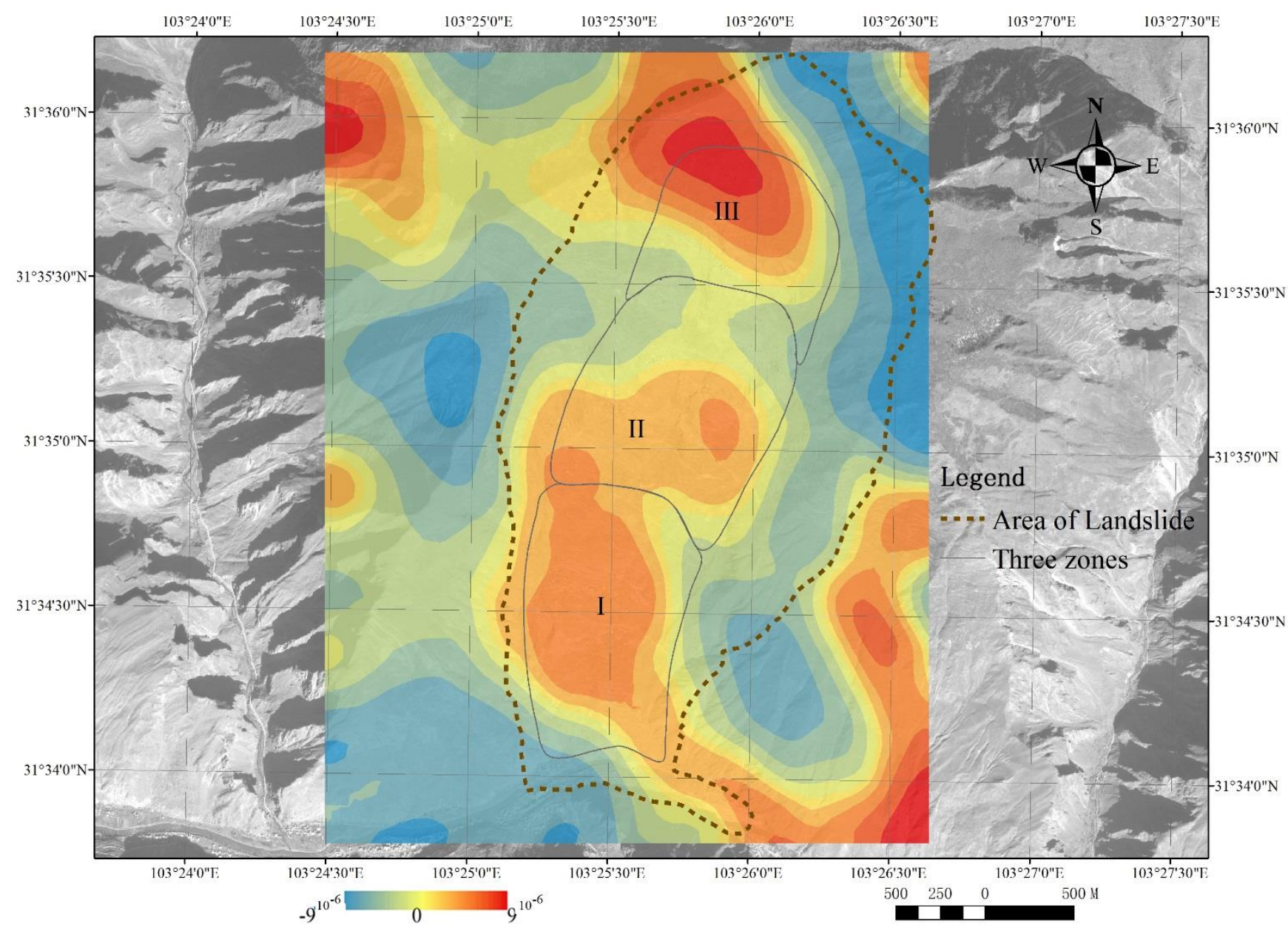

Fig. 5 Map of change in area (Three zones -- local perturbations with faults; I: Obvious deformations at the front edge of the landslide; II: mid part of the landslide with cracks and fissures; III: the trailing edge of the landslide with enriched materials)

\section{Discussion}

In this case study, important deformation results on the Xishan landslide have been obtained, which contribute to a better understanding of the physical behavior and process couplings of slow-moving landslides. The proposed work has several advantages for very high-resolution imagery analysis of landslides. First, 2D horizontal displacements are derived from the DIC compared with the displacement from DEM differencing. The result demonstrates the potential of this technique by identifying the heterogeneous displacement field of the landslide in space and time. Secondly, determined with the 2D Cauchy strain tensor, the 2D displacements can be further applied to strain computations to characterize possible strain localization and material behavior in the damaging zone. Thirdly, the strain analysis of a landslide highlights eventual different behavior of various zones of the studied area. In particular, the kinematics across a fault can be analyzed, or the boundaries of the zones or a landslide having different kinematics can be detected.

The power of the strain analysis of a landslide by means of data on ground surface motion is enhanced when the studied phenomenon is particularly complex, with very different kinematics. In particular, the zones with different kinematics can be detected (Fig. 6), and the tensional state of the ground surface and shallow layer of the unstable slope can be studied. Such information is useful for real-time monitoring. According to the three zones recognized by means of the strain analysis, spatial distribution of a borehole for in-situ real-time monitoring and GPS was mapped on Fig. 6. Since June 16, 2014, the 
$103^{\circ} 25^{\prime} 0^{\prime \prime} \mathrm{E} \quad 103^{\circ} 25^{\prime} 10^{\prime \prime} \mathrm{E} \quad 103^{\circ} 25^{\prime} 20^{\prime \prime} \mathrm{E} \quad 103^{\circ} 25^{\prime} 30^{\prime \prime} \mathrm{E} \quad 103^{\circ} 25^{\prime} 40^{\prime \prime} \mathrm{E} \quad 103^{\circ} 25^{\prime} 50^{\prime \prime} \mathrm{E} \quad 103^{\circ} 26^{\prime} 0^{\prime \prime} \mathrm{E} \quad 103^{\circ} 26^{\prime} 10^{\prime \prime} \mathrm{E} \quad 103^{\circ} 26^{\prime} 20^{\prime \prime} \mathrm{E} \quad 103^{\circ} 26^{\prime} 30^{\prime \prime} \mathrm{E} \quad 103^{\circ} 26^{\prime} 40^{\prime \prime} \mathrm{E}$

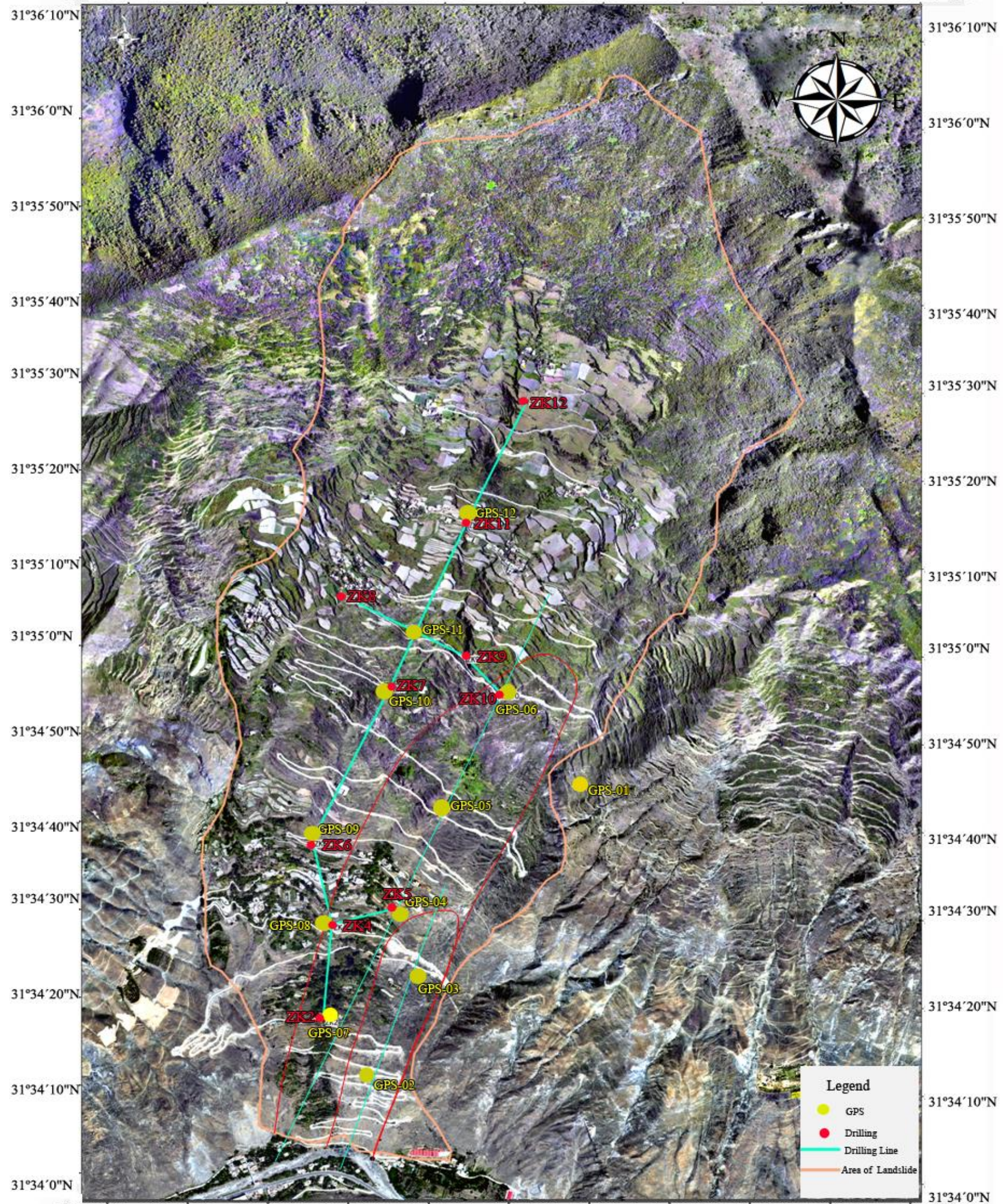

$103^{\circ} 25^{\prime} 0^{\prime \prime} \mathrm{E} \quad 103^{\circ} 25^{\prime} 10^{\prime \prime} \mathrm{E} \quad 103^{\circ} 25^{\prime} 20^{\prime \prime} \mathrm{E} \quad 103^{\circ} 25^{\prime} 30^{\prime \prime} \mathrm{E} \quad 103^{\circ} 25^{\prime} 40^{\prime \prime} \mathrm{E} \quad 103^{\circ} 25^{\prime} 50^{\prime \prime} \mathrm{E} \quad 103^{\circ} 26^{\prime} 0^{\prime \prime} \mathrm{E} \quad 103^{\circ} 26^{\prime} 10^{\prime \prime} \mathrm{E} \quad 103^{\circ} 26^{\prime} 20^{\prime \prime} \mathrm{E} \quad 103^{\circ} 26^{\prime} 30^{\prime \prime} \mathrm{E} \quad 103^{\circ} 26^{\prime} 40^{\prime \prime} \mathrm{E}$

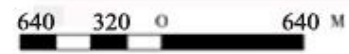

Fig. 6 Distribution of in-situ geotechnical sensors and GPS of monitoring locations 


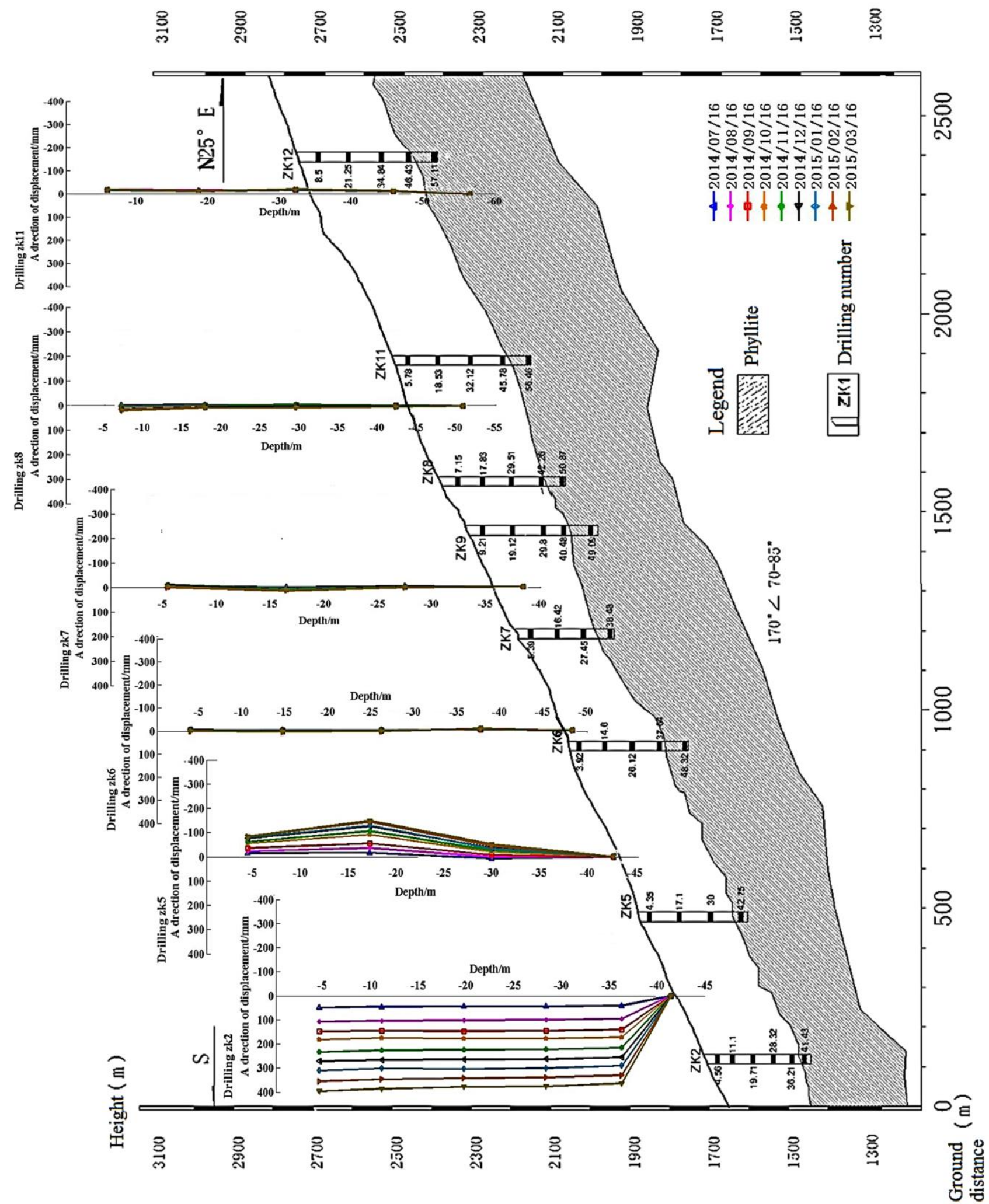

Fig. 7 Cumulative displacement of inclinometers 
data on geotechnical sensors (inclinometer, rain gauge, and pore pressure gauge) have been acquired and transited. Continuous and traceable real-time monitoring data can improve comprehensive monitoring of underground deformation. Inclinometers are used to continuously monitor the entire vertical extent of the landslide. Recent boreholes, up to $45 \mathrm{~m}$ deep, show that the bedrock is constituted of silty and clayey marls overlaying. Phyllite is at a depth of about $70 \mathrm{~m}$ from the ground surface. The observations from inclinometers reflect the realtime changes in the internal slope, and may allow a better understanding of landslide mechanism. The results of dual-axis inclinometer in drilling ZK2 and ZK5 located in area I and II showed the greater cumulative displacements of in-depth movements (Fig. 7) during the period, which indicated dangerous deformation area of Xishan landslide located in the area within red lines in Fig. 6. Horizontal surface displacement monitoring with complete overview of vertical micro movements can improve the monitoring system effectiveness and allow in-depth analysis of the phenomena before the paroxysmal phase. Furthermore, continuous displacements can demonstrate correlation analysis with the information derived from pore water pressure and rain gauge to confirm whether Xishan landslide accelerations are controlled by hydro-climatic conditions and whether the long-term behavior is characterized by continuous movements with a seasonal trend.

Later in 2015, differential GPS (dGPS) surveys of blocks were distributed in the study area. Given the condition of in-situ, data of GPS 07, GPS09 and GPS11 were acquired during Dec 14, 2015 Jan 22, 2016. Deformation directions from GPS07, GPS09 and GPS11 were about $203.8^{\circ}, 207.1^{\circ}$ and $185.3^{\circ}$, respectively. Results of cumulative displacement indicated that I and II area had great deformation (Fig. 8). According to the result of GPS survey, Xishan landslide deformation analysis based on pixel tracking on VHR images shown in the present study concerning rate changes appear to be generally robust; however, absolute displacement amplitudes and directions need to be considered carefully. Future research has to combine TLS to achieve 3D displacement monitoring.

Notably, errors in displacement computation and in strain computation could be dominated by the georeferencing errors. Errors that affect the deformation analysis procedure is also an interesting area to investigate.

\section{Conclusion}

This study shows that VHR satellite data can be a useful or even unique information source of displacement and strain rates in both spatial and temporal dimensions. The findings can contribute to a better understanding of the physical behavior and process couplings of active, slow-moving landslides. The deformation indicates that prefailure strains can be potentially useful precursors of main movements. Continuous strain measurements could contribute to understanding the failure mechanism and the calibration or validation of coupled hydro-mechanical deformation models. Strain could be directly observed through "object-oriented analysis" on very high-resolution orthoimages.

The results were based on the reduction of a 3D displacement field to a 2D optical image. Future studies are recommended to explore the possibility of 3D correlating and validating strain analysis data with other remote-sensing data sources.

\section{Acknowledgements}

This work was supported by National Basic Research Program of China (Project No. 2013CB733204) and the Innovation Program of Shanghai Municipal Education Commission (No. 14ZZ172). 


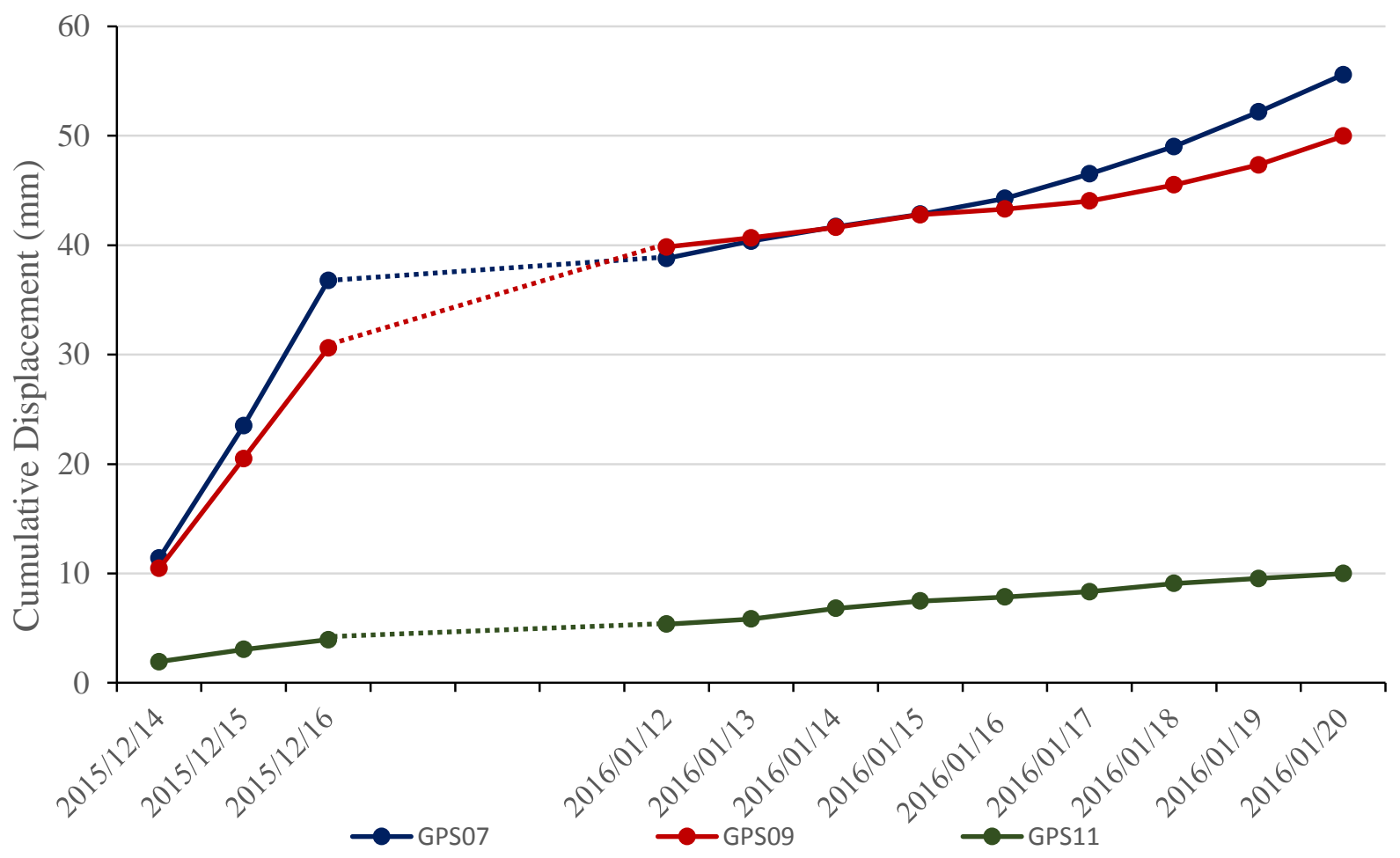

(a) Horizontal cumulative displacement gained from GPS surveying

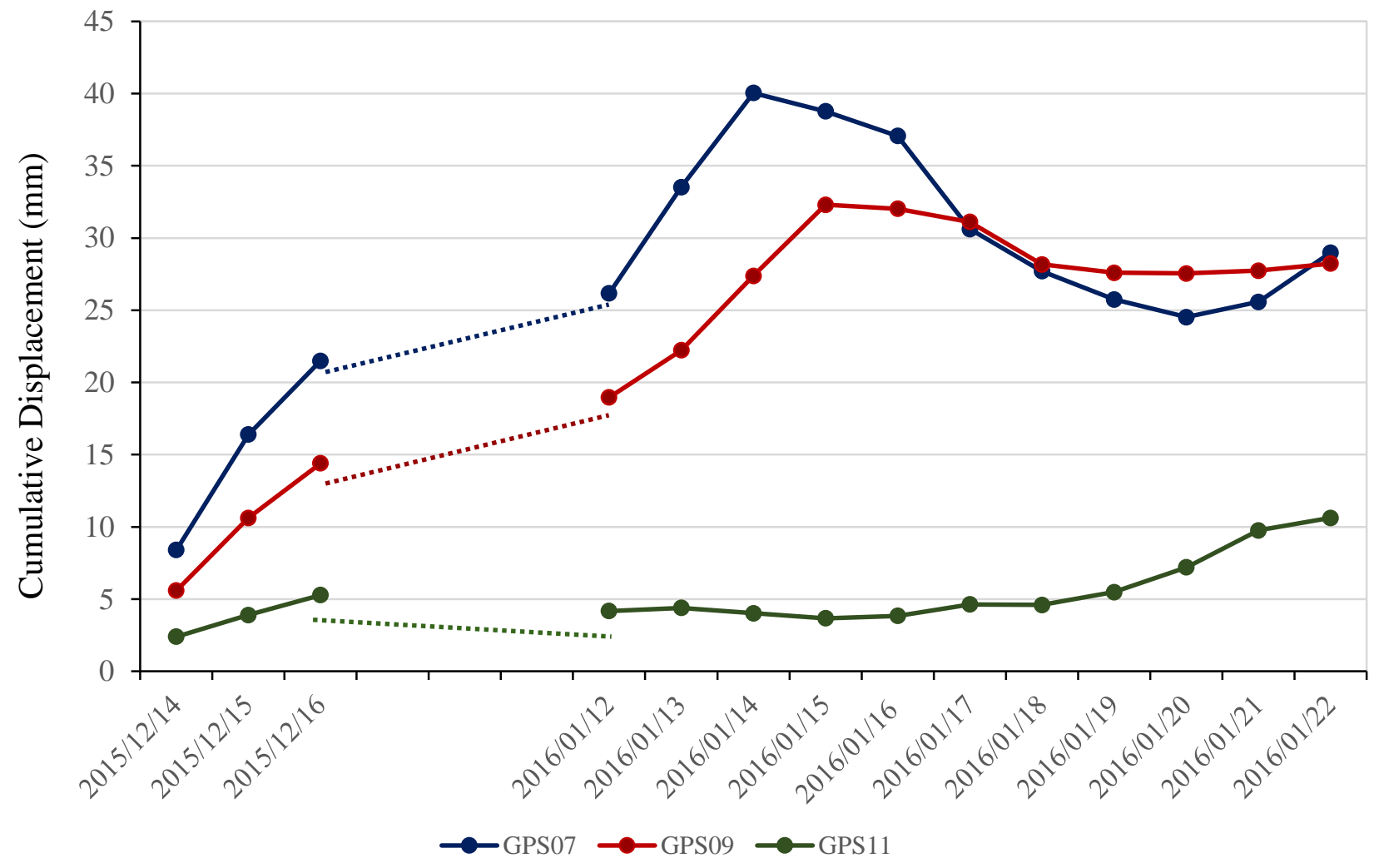

(b) Vertical cumulative displacement obtained from GPS surveying

Fig. 8 Cumulative displacement shown in GPS surveys (data from Dec 17, 2015 to Jan 11, 2016 was missing) 


\section{References}

Antonello, G., N. Casagli, P. Farina, D. Leva, G. Nico, A. Sieber and D. Tarchi, 2004. Groundbased SAR interferometry for monitoring mass movements. Landslides, 1(1): 21 - 28.

Abellán, A., M. Jaboyedoff, T. Oppikofer and J. Vilaplana, 2009. Detection of millimetric deformation using a terrestrial laser scanner: experiment and application to a rockfall event. Natural Hazards and Earth System Science, 9(2): 365 - 372.

Ayoub, F., S. Leprince and L. Keene, 2009. User's Guide to COSI-CORR Co-registration of Optically Sensed Images and Correlation. California Institute of Technology: Pasadena, CA, USA: 38.

Baroň I., R. Supper, et al. 2012. Report on evaluation of mass movement indicators. 7th Framework Programme Cooperation Theme 6 Environment (including climate change) SubActivity 6.1.3 Natural Hazards. 2012. 04. 17

Booth, A.M., M.P. Lamb, J.P. Avouac and C. Delacourt, 2013. Landslide velocity, thickness, and rheology from remote sensing: La Clapière landslide, France. Geophysical Research Letters, 40(16): 4299 - 4304.

Casson, B., C. Delacourt and P. Allemand, 2005. Contribution of multi-temporal remote sensing images to characterize landslide slip surface. Application to the La Clapière landslide (France). Natural Hazards and Earth System Science, 5(3): 425 - 437.

Colesanti, C. and J. Wasowski, 2006. Investigating landslides with space-borne Synthetic Aperture Radar (SAR) interferometry. Engineering Geology, 88(3): 173 - 199.

Crosetto, M., J. Gili, O. Monserrat, M. CuevasGonzález, J. Corominas and D. Serral, 2013. Interferometric SAR monitoring of the Vallcebre landslide (Spain) using corner reflectors. Natural Hazards and Earth System Science, 13(4): 923 - 933.

Debella-Gilo, M. and A. Kääb, 2011. Sub-pixel precision image matching for measuring surface displacements on mass movements using normalized cross-correlation. Remote Sensing of Environment, 115(1): 130 - 142.
Delacourt, C., P. Allemand, B. Casson and H. Vadon, 2004. Velocity field of the "La Clapière" landslide measured by the correlation of aerial and QuickBird satellite images. Geophysical Research Letters, 31(15), L15619. DOI:10.1029/2004GL020193.

Delacourt, C., P. Allemand, E. Berthier, D. Raucoules, B. Casson, P. Grandjean, C. Pambrun and E. Varel, 2007. Remote-sensing techniques for analysing landslide kinematics: a review. Bulletin de la Société Géologique de France, 178(2): 89 - 100.

ENVI 5.0, 2012. http://www.exelisvis.com/IntelliEarthSolutions /GeospatialProducts /ENVI.aspx

Farina, P., J.A. Avila-Olivera, V.H. GarduñoMonroy and F. Catani, 2008. DInSAR analysis of differential ground subsidence affecting urban areas along the Mexican Volcanic Belt (MVB). Rivista Italiana di Telerilevamento (AIT), Il Telerilevamento a microonde, L'attività di ricerca e le applicazioni, 40(2): 103 - 113.

Heid, T. and A. Kääb, 2012. Evaluation of existing image matching methods for deriving glacier surface displacements globally from optical satellite imagery. Remote Sensing of Environment, 118: 339 - 355.

Herrera, G., J. Fernández-Merodo, J. Mulas, M. Pastor, G. Luzi and O. Monserrat, 2009. A landslide forecasting model using ground based SAR data: The Portalet case study. Engineering Geology, 105(3): 220 - 230.

Hild, F. and S. Roux, 2008. CorreliQ4: Software for finite element displacement field measurements by digital image correlation. Rapport interne LMT Cachan, 269.

Kasperski, J., C. Delacourt, P. Allemand, P. Potherat, M. Jaud and E. Varrel, 2010. Application of a terrestrial laser scanner (TLS) to the study of the Séchilienne Landslide (Isère, France). Remote Sensing, 2(12): 2785 - 2802.

Kääb, A, 2013. Image correlation software CIAS. http://www.mn.uio.no/icemass (last access: 9 January 2015).

Kimura, H. and Y. Yamaguchi, 2000. Detection of landslide areas using satellite radar 
interferometry. Photogrammetric Engineering and Remote Sensing, 66(3): 337 - 344.

Leprince, S., F. Ayoub, Y. Klinger and J.P. Avouac, 2007. Co-registration of optically sensed images and correlation (COSI-Corr): An operational methodology for ground deformation measurements. Geoscience and Remote Sensing Symposium, IGARSS 2007, Barcelona, Spain. IEEE International.

Lu, P., N. Casagli., F. Catani and V. Tofani, 2012.

Persistent Scatters Interferometry Hotspot and Cluster Analysis (PSI-HCA) for detection of extremely slow-moving landslides. International Journal of Remote Sensing, 33(2): 466 - 489.

Lu, P., F. Catani, V. Tofani, and N. Casagli, 2014. Quantitative hazard and risk assessment for slow-moving landslides from Persistent Scatter Interferometry. Landslides, 11(4): 685 - 696.

Massonnet, D. and K.L. Feigl, 1998. Radar interferometry and its application to changes in the Earth's surface. Reviews of GeophysicsRichmond Virginia Then Washington, 36(4): 441 - 500.

Michel, R. and J.P. Avouac, 2002. Deformation due to the 17 August 1999 Izmit, Turkey, earthquake measured from SPOT images. Journal of Geophysical Research: Solid Earth (1978-2012), 107(B4): ETG 2-1 - ETG 2-6.

Medicis, https://entreprises.cnes.fr

Monserrat, O., J. Moya, G. Luzi, M. Crosetto, J. Gili and J. Corominas, 2013. Noninterferometric GB-SAR measurement: application to the Vallcebre landslide (eastern Pyrenees, Spain). Nat. Hazard. Earth Syst, 13: 1873 - 1877.

Mora, P., P. Baldi, G. Casula, M. Fabris, M. Ghirotti, E. Mazzini and A. Pesci, 2003. Global Positioning Systems and digital photogrammetry for the monitoring of mass movements: application to the Ca'di Malta landslide (northern Apennines, Italy). Engineering Geology, 68(1): 103 - 121.

Nagler, T., H. Rott and A. Kamelger, 2002. Analysis of landslides in Alpine areas by means of SAR interferometry. Geoscience and Remote Sensing Symposium. IGARSS'02, Toronto, Ontario. IEEE International.
Pan, B., K. Qian, H. Xie and A. Asundi, 2009. Two-dimensional digital image correlation for in-plane displacement and strain measurement: a review. Measurement Science and Technology, 20(6): 1 - 17.

Pierrot-Deseilligny, M. and N. Paparoditis, 2006. A multiresolution and optimization-based image matching approach: An application to surface reconstruction from SPOT5-HRS stereo imagery. Archives of Photogrammetry, Remote Sensing and Spatial Information Sciences 36 (1/W41).

Pierrot-Deseilligny, M, 2014. MicMac. Apero, Pastis and Other Beverages in a Nutshell. http://logiciels.ign.fr/?Micmac

PICMATCH, http://wwwmipl.jpl.nasa.gov/vicar/core390/html/vichelp/p icmatch.html

Pollard, D.D. and R.C. Fletcher, 2005. Fundamentals of structural geology: Cambridge University Press.

Rosu, A.M., M. Pierrot-Deseilligny, A. Delorme, R. Binet and Y. Klinger, 2014. Measurement of ground displacement from optical satellite image correlation using the free open-source software MicMac. ISPRS Journal of Photogrammetry and Remote Sensing, 100: 48 $-59$.

Stumpf, A., J.P. Malet, P. Allemand and P. Ulrich, 2014. Surface reconstruction and landslide displacement measurements with Pléiades satellite images. ISPRS Journal of Photogrammetry and Remote Sensing, 95: 1 12.

Teza, G., A. Pesci, R. Genevois and A. Galgaro, 2008. Characterization of landslide ground surface kinematics from terrestrial laser scanning and strain field computation. Geomorphology, 97 (3): 424 - 437.

Travelletti, J., C. Delacourt, P. Allemand, J.P. Malet, J. Schmittbuhl, R. Toussaint and M. Bastard, 2012. Correlation of multi-temporal ground-based optical images for landslide monitoring: Application, potential and limitations. ISPRS Journal of Photogrammetry and Remote Sensing, 70: 39 - 55.

Travelletti, J., J.P. Malet and C. Delacourt, 2014. Image-based correlation of Laser Scanning point cloud time series for landslide monitoring. 
International Journal of Applied Earth Observation and Geoinformation, 32: 1 - 18.

Tsai, Z.X., G. J.Y. You, H.Y. Lee and Y.J. Chiu, 2012. Use of a total station to monitor postfailure sediment yields in landslide sites of the Shihmen reservoir watershed, Taiwan. Geomorphology, 139: 438 - 451.

Van Puymbroeck, N., R. Michel, R. Binet, J.P. Avouac and J. Taboury, 2000. Measuring earthquakes from optical satellite images. Applied Optics, 39(20): 3486 - 3494.
Watson, A., D. Moore and T. Stewart, 2004. Temperature influence on rock slope movements at Checkerboard Creek. Landslides: Evaluation and Stabilization, Proceedings of the 9th International Symposium on Landslides, Rio de Janeiro, Brazil.

Wattrisse, B., A. Chrysochoos, J.M. Muracciole and M. Némoz-Gaillard, 2001. Analysis of strain localization during tensile tests by digital image correlation. Experimental Mechanics, 41(1): 29 - 39. 